\title{
When is a lie more of a lie? Moral judgment mediates the relationship between perceived benefits of others and lie-labeling
}

\begin{abstract}
Lay perceptions of lying are argued to consist of a lie prototype. The latter was found to entail the intention to deceive, belief in falsity and falsity (Coleman \& Kay, 1981). We proposed and found that the perceptions of the benefits of others are also an important factor that influences the extent, to which an act of intentional misleading someone to foster a false belief is labeled as a lie. Drawing from the intuitionist model of moral judgments (Haidt, 2001) we assumed that moral judgment of the behaviour would mediate the relationship. In Study 1 we analyzed data coming from a crosscultural project and found that perceived intention to benefit others was negatively related to lie labeling and that this relationship was mediated by the moral judgment of that act. In Study 2 we found that manipulating the benefits of others influenced the extent, to which an act of intentional misleading in order to foster a false belief is labeled as a lie and that, again, this relationship is mediated by the moral judgment of that act.
\end{abstract}

Key words: prototype, lying, egoistic, other-oriented, lay definition, deception

\section{Introduction}

Is it a lie to tell your supervisor that you are busy when asked if you can work extra hours? Most would probably agree that if, in fact, you would have time to do it but simply did not feel like it and you preferred that your colleague stayed late at work, than yes, it is a lie. What if you are saying this because you know that your colleague is in urgent need of money and would like your colleague to get these extra paid work hours? Though in both cases you are deviating from the truth, the beneficiary of the lie is not the same. In this paper we aim to show that the extent to which the act of deviating from the truth in order to foster a false belief is considered a lie depends on whether the act benefits oneself or another person and that this relationship is mediated by the moral judgment of that act.

\section{Defining Lying}

Many researchers agree that a lie occurs when someone tries to intentionally mislead somebody else (DePaulo, Kashy, Kirkendol, Wyer, \& Epstein, 1996; see also Buller \& Burgoon, 1996; Ekman, 1985). Masip, Garrido and Herrero (2004) analyzed definitions of lying, which were authored by other researchers in the field, and proposed a definition that is useful for social science researchers. This definition included all sufficient and necessary factors that need to be present so that we can define an act as lying. They define lying as 'the deliberate attempt, whether successful or not, to conceal, fabricate, and/or manipulate in any other way factual and/or emotional information, by verbal and/or nonverbal means, in order to create or maintain in another or in others a belief that the communicator himself or herself considers false' (Masip et al., 2004, p. 148).

Masip et al. (2004) equalize the term 'lie' to 'deception' and 'deceptive communication'. However, the term 'deception' is much broader and also traditionally contains acts of non-intentional misleading, as is the case, for example, in mimicry (e.g., Holling, 1965). Interestingly, there is research that provides arguments for intentional deception in animals (see, e.g., Bugnyarf1 \& Kotrschal, 2002; Kuczaj, Tranel, Trone, \& Hill, 2001).

\footnotetext{
* SWPS University of Social Sciences and Humanities, Faculty in Sopot, Polna 16/20, 81-745 Sopot, Poland

** Institute of Psychology, Polish Academy of Sciences

Corresponding author: Katarzyna Cantarero
}

This article was written thanks to research grant Preludium awarded to Katarzyna Cantarero by National Science Centre in Poland The grant title was 'Cross-cultural differences in the acceptance of lying in view of the Moral Foundations Theory', no. 2011/01/N/HS6/02211. 
The word 'deception' is also used widely with regards to methodological and ethical issues regarding conducting scientific research in the social sciences (e.g., Berscheid, Abrahms, \& Aronson, 1967; Schwab, 2013). In particular, the issue of introducing a cover story while conducting research is considered a form of deception. For the sake of clarity, we will limit our subjects of study to humans and we will use the term 'lying' to describe acts of intentional misleading to foster a false belief.

The definition of lying proposed by Masip et al. (2004) points to aspects that are thought as crucial to correctly distinguish lying from similar acts. It seems that the aspect of intentionality is by far the most important when analyzing the definition of lying. Misinformation without deliberate intent could be a result of an unintentional mistake or lack of competence (see also Ekman, 1985). The definition also proposes that different forms of communication should be treated as lies and that this includes both producing false statements and concealment. However, some researchers argue that the latter would be better defined as keeping a secret and thus should not be considered a lie (Bok, 1982). Additionally, by definition, lying does not even require verbal statements, as even nonverbal communication may involve lying.

There is an important factor related to defining lying that Ekman calls 'prior notification of an intention' to lie (Ekman, 1985, p. 27). In some social situations it is expected that the communicator will pass on information that does not necessarily reflect one's personal point of view. When prior notification of an intention to lie is present, then the act itself should not be called a lie. The author gives examples of going to the theatre or playing card games. For example, people generally know that while in a play, any declarations of the actors are not intended to reflect true, personal opinions and thus behavior contrary to that declaration (either in the play or in the real life), should not be named a lie. Similarly, some social situations are thought to offer a sort of waiver of social norms that does not treat acts of intentional misleading as lying. In a daily diary study on lying conducted in the United States by DePaulo et al. (1996), participants were asked to maintain diaries for the course of one week and record each of their social interactions that lasted 10 minutes or longer and every lie a participant told (regardless of the length of the interaction). The authors decided not to count as lies (and asked participants not to record) the instances when participants answered 'I'm fine, thank you!' to the question 'How are you?', even if in reality the participant did not feel fine. This was due to the fact that it is considered a social norm to respond to that question with a positive answer. We may expect interesting differences in social perceptions of whether an act of intentionally misleading someone to foster a false belief is indeed viewed as a lie and is not a cultural norm, subject to prior notification of the intention to lie (Kim, Kam, Sharkey, \& Singelis, 2008). Let's take the example of Poland, a country where people tend to state that they feel worse than average (Dolinski, 1996) and where the social norm is to complain (e.g., Wojciszke \& Baryła, 2002). It is possible that if someone in Poland is feeling great but answers 'I'm so-so' to the question 'How are you?', then that answer would not be considered a lie.

There is also an intriguing relationship between falsehood, truth and lying. Some researchers state that lies are false statements (e.g., Sweetser, 1987). From the perspective of logic, falsehood does not necessarily mean lying and vice versa (Antas, 2008). For example, logic indicates that a sentence is true when just one of the elements of an alternative is true. This means that if $p$ is true, then p v q is true. However, as Antas (2008) indicates, this does mean that the statement is pragmatically true. If person $\mathrm{X}$ is asked who stole the money and s/he knows that $\mathrm{Y}$ stole the money, but $\mathrm{s} /$ he says that $\mathrm{Y}$ or $\mathrm{Z}$ stole the money, then such a statement is not logically false, when pragmatically it is not true and it is misleading (Antas, 2008). There is also an unobvious existence of lies based on truth (see also Cantarero, 2014). For example, let us imagine a situation where a child asks his mother if they can go to the cinema. The mother, unwilling to fulfill the child's request that day, says that they cannot do it, because the cinema is closed, although she is convinced that it is open. An example of a lie based on truth would be if, that day, the cinema would actually be closed, although the mother did not know it. As the definition of Masip et al. (2004) indicates, it is the belief that the information is not true and not its objective falsity that constitutes lying. This is the case with scientific definitions of lying. Lay definitions do not need to be exactly the same.

\section{Lay Definitions of Lying and Lying Acceptance}

The definition of lying presented above was a scientific way to operationalize the concept of lying. We would like to now turn to lay definitions of lying and show that they are somewhat different to the scientific ones. Lies are present in everyday life and most people tend to lie every day (DePaulo et al., 1996). Thus, to some extent, people might be perceived as experts regarding lying. Yet, people are also the 'users' of the laws of physics and lay theories regarding the laws of physics are far from accurate (McCloskey, 1983). Therefore, we think that it is important to make a clear distinction between lay and scientific definitions of lying.

Research on lay definitions of lying showed that the most prototypical lies are the ones that entail falsehood of the communication, belief that the communication is false, and the intention to deceive (Coleman \& Kay, 1981). Coleman and Kay (1981) showed that to be perceived as a lie, a behavior does not need to include all three factors at once. Behaviors were named as lies to a higher extent when they contained more of the elements. Belief in falsehood was found to be most important, followed by the intention to deceive and, finally, objective falsity. The findings of Coleman and Kay were also tested in a crosscultural setting and showed that the notion of a prototypical lie is shared in other cultures (Hardin, 2010; Eichelberger, 2013). The aspect of objective falsity was also recently tested by Turri and Turri (2015). Their research suggests 
that objective falsity is indeed important for an act to be perceived as a lie. The findings on prototype lies are important not only because they show the factors on which lay definitions of lying are based, but also because they suggest that people perceive some acts as lies more than others. Thus, lay definitions of lying are not of a zero-one type, but we can analyze the extent to which something is perceived as a lie.

There is research that shows that merely labeling a behavior as a lie has an influence on the extent to which that behavior is found acceptable (Cheung, Chan, \& Tsui, 2016; Wimmer, Gruber, \& Perner, 1985). In an interesting study conducted on children, Cheung, Chan and Tsui (2016) showed that when participants were presented with a description of a behavior that was egoistic, polite or altruistic, adding a label that the behavior was a lie lowered moral judgment of such a behavior. Importantly, lie labeling influenced only the moral evaluation of polite and altruistic lies. Cheung, Siu and Chen (2015) conducted a study on lie labeling with both children and adults. The authors presented participants with stories that were either truthful statements or lies regarding opinion or reality. Additionally, the lies were either prosocial or egoistic. Participants were asked to decide whether the protagonist of a story lied and they were asked to give their moral evaluation of that behavior. The results showed that children varied in their categorization of whether an act was a lie or not (not always lies were categorized as lies). The adults, however, identified stories that were written to depict lies as lies and stories presenting truths as truths. The researchers conducted an additional analysis on the children's data, where they showed that the identification of a lie and the moral judgment of that behavior were positively related.

Research shows that the acceptance of lying depends on whether the lie is self-centered or of benefit to others (e.g., Fu, Xu, Cameron, Heyman, \& Lee, 2007; Lee, Cameron, Xu, Fu, \& Board, 1997). People find lies that are aimed at protecting others to be the most acceptable, whereas lies that benefit the liar but hurt another person are found to be least acceptable (Lindskold \& Walters, 1983). These studies indicate that the beneficiary of the lie (self vs. others) is crucial for the moral judgment of lies.

\section{The Content and the Process of Moral Judgments}

There is a debate as to which factors are the most relevant for people's moral judgments (for an overview, see Wojciszke, Parzuchowski, \& Bocian, 2015; Parzuchowski, Bocian, \& Wojciszke, 2016). Moral Foundations Theory stands in the position of a domain-specific content that is relevant for moral judgments (Haidt, 2012; Graham et al., 2013; Graham et al., 2011). The authors draw from the works of Shweder, who argued that there is more than one, individualistic moral code (Shweder, Mahapatra, \& Miller, 1987; Shweder, Much, Mahapatra, \& Park, 1997). Moral Foundations Theory proposes that there is a set of innate moral foundations that is decisive in evaluating whether an act is bad or not. They argue that moral judgments are mainly based on considerations regarding harm, fairness, loyalty, authority and purity (Haidt, 2012). These intuitions are also vulnerable to cultural and social influence (Haidt, \& Joseph, 2004). For example, research has shown that while liberal American students based their moral judgments mainly on considerations of harm or lack thereof, Brazilians provided negative moral judgments when an act was also found to be impure (Haidt, Koller, \& Dias, 1993).

Dyadic morality is a somewhat different approach to the basis of moral judgments. In the authors' view, consideration of harm is the determining factor for moral judgments (Gray \& Schein, 2012). They posit that even when an act of wrongdoing is not explicitly directed at harming someone, it still increases perceptions of suffering and activates the concept of harm (Gray, Schein, \& Ward, 2014). The authors argue that acts of wrongdoing that ostensibly lack victims are perceived as incomplete and thus result in dyadic completion, which is thought to automatically and implicitly involve 'adding' a victim. The dyadic morality approach also stands in the position of nativism on the one hand and the possibility of cultural variation on the other (Gray, Young, \& Waytz, 2012). Though the approach is domain-general, it does embrace pluralism. Namely, harm pluralism, according to the authors, is responsible for the variation regarding when and where some people perceive certain acts as harmful (Gray \& Keeney, 2015).

Thus, it seems that perceptions of harm are undoubtedly a very important factor for the formation of moral judgments (Gray \& Schein, in press). Though Gray and Graham may differ in the way they define what moral judgments depend on, the idea that moral judgments are formed in a fast, effortless way seems to be shared regardless of the (dis)agreement over the predictors of moral judgments (see Gray \& Keeney, 2015; Haidt, 2001). The traditional point of view perceived moral judgments as a result of thorough argumentation (e.g., Kohlberg, 1976; Kohlberg \& Hersh, 1977). The intuitionist model of moral judgments posits that moral judgments resemble more of a gut feeling than rational argumentation (Haidt, 2001). Moral intuition influences the moral judgment and moral reasoning comes in the form of arguments that back up the already made moral judgment. Haidt (2012) claims that in their moral judgments people resemble lawyers trying to argue for an already made position more than impartial scientists. The intuitionist model of moral judgment has important implications for lay definitions of lying.

The word 'lie' is in itself evaluated negatively and thus the mere appearance of the word can trigger more negative evaluations. Research by Cheung et al. (2016) indeed confirms that merely labeling a behavior as a lie can influence its evaluation. It seems though that this relationship may go both ways. If we take into consideration the intuitionist model of moral judgments, it seems likely that the act of labeling something as a lie may be a consequence of deciding whether the act itself is good or bad. Interestingly, research shows that lying for the benefit of others is perceived as more ethical than bluntly telling the truth (Levine \& Schweitzer, 2014). Moral judgment of a behavior 
depends on whether the act brings benefits to another person (Schein, Goranson, \& Gray, 2015). The degree to which a behavior that is an intentional act of misleading someone to foster a false belief brings benefits to others should have consequences for both moral judgments and evaluations of deceitfulness. Additionally, drawing from the intuitionist model of moral judgments, the moral judgment should happen rather quickly and without effort. The argumentation and reasons why the act is good/bad are thought to come after the moral judgment and not precede it.

To the best of our knowledge, we are the first to test the influence of the perceived benefits of others on the extent to which an act of intentionally misleading someone in order to foster a false belief is perceived as a lie. In their work, Levine \& Schweitzer (2014) showed that people perceive prosocial lying as more ethical than truth telling. The authors did not focus, however, on the perceptions of definitions of the acts. Importantly, we wanted to focus on perceptions of the extent to which that behavior is perceived as a lie. The study of Cheung, Siu and Chen (2015) used a dichotomous categorization of whether an act is a lie. Had the adult participants had a chance to rate perceptions of the extent to which an act of intentionally misleading someone in order to foster a false belief is a lie, it is possible that the prosocial lies could have been perceived as less of a lie than the egoistic lies. Additionally we think that this relationship should be mediated by the extent to which the behavior is perceived as good. Theoretical considerations and empirical research regarding the formation of moral judgments provide strong arguments for the fact that the moral judgment happens quickly and the rational argumentation comes afterwards. As a consequence, in the case of acts of intentionally misleading someone in order to foster a false belief, the judgment of whether that act is a lie could be treated as argumentation following the moral judgment. For this reason we assumed that the most theoretically correct path of the relationship would go from the perception of benefits/harm to others, through moral judgment to identification of the extent to which a behavior is a lie.

In a previous paper we showed that there is a positive correlation between lying acceptability and the extent to which a behavior can be labeled a lie (Cantarero, Szarota, Stamkou, Navas, \& Dominguez Espinosa, in press). We wanted to expand on that thought and focus on the prerequisites of naming something a lie. Most importantly, we wanted to show that lie-labeling an act of intentionally misleading someone in order to foster a false belief is influenced by the perception of benefits of others related to that behavior.

\section{Method}

The aim of the studies was to test whether the benefits of others influence the extent to which people define an act of intentionally misleading someone in order to foster a false belief as lying and whether this relationship is mediated by the moral judgment. To test the hypothesis, we first focused on correlational data coming from a crosscultural project on attitudes towards lying (Study 1). We then conducted an experiment, where we manipulated perceived benefits of others related to the act of intentionally misleading someone in order to foster a false belief (Study 2).

\section{Study 1}

\section{Participants and Procedure}

The data presented here were gathered as a part of a project on cross-cultural differences in attitudes towards lying (Cantarero et al., in press). To be able to answer the research question, we focused on the data gathered in the project. The project aimed to show that attitudes towards lies in a cross-cultural context depend on the type of lie (its beneficiary and its context) and that moral judgment of a lie depends both on cultural differences and individual differences in moral foundations. This part of project is described elsewhere (Cantarero et al., in press). In this paper, we only address the issue of the predictors of the extent to which a behavior is described as a lie.

There were 1482 students from Mexico, Spain, Ireland, Estonia, The Netherlands, Sweden and Poland that participated in the study. The data were gathered at university venues in the seven countries. First, we analyzed missing data. We excluded cases with more than $5 \%$ of missing data. This resulted in the final sample consisting of replies from 1345 participants, which included 211 students from Mexico (166 women), 203 from Spain (137 women), 169 from Ireland (93 women), 196 from Estonia (133 women), 197 from The Netherlands (125 women), 169 from Sweden (97 women) and 200 from Poland (135 women). There were replies from 886 women and 454 men in the data ( 5 people did not state their gender). The mean age of the participants was $22.40\left(S D_{\text {age }}=4.51\right)$.

\section{Materials}

Participants were asked to read and evaluate twentyseven stories that were previously designed to represent lies (Cantarero et al., in press). We never used the word 'lie' or 'deception' when describing the behavior presented in the stories. An example story of an egoistic lie: Person A, when asked for help by person B, says that he/she cannot help because he/she has a fever, and has to rest, even though in reality he/she feels good. An example of an other-oriented lie: Person A tells person B (superior of person A and person C) that person $C$ went to the toilet, even though in fact person $C$ was late to work. ${ }^{1}$

We measured moral judgment on a scale from $1=\operatorname{good}$, to $7=\mathrm{bad}$. Additionally, participants were asked to give their evaluation of the behavior of the story's protagonist (person A, the liar) towards person B as: 1 = acceptable, 7 = unacceptable; 1 = typical, $7=$ untypical; $1=$ important, $7=$ unimportant; the

\footnotetext{
1 The stories in various language versions are available upon request from the corresponding author.
} 
motivation for bringing benefits to person A $1=$ definitely yes, 7 = definitely not; the motivation for bringing benefits to person B 1 = definitely yes, 7 = definitely not. Finally, participants were asked to state to what degree they considered the protagonist's behavior as lying, where $0=$ definitely not a lie and $100 \%=$ definitely a lie. In stories where a person $\mathrm{C}$ appeared, participants were also asked to state to what degree they felt person A's behavior was motivated by the desire to bring benefits to person $\mathrm{C}$ : $1=$ definitely yes, 7 = definitely not.

Participants were also asked to provide demographic data (age, gender, nationality, education, religion, marital status and religiosity on a $1=$ definitely religious to 7 = definitely not religious scale).

\section{Results}

First, we recoded the data so that a higher number was indicative of the higher degree to which a behavior was assessed as good, bringing benefits to the liar and bringing benefits to another person. We then calculated mean replies of the before mentioned variables and the mean reply regarding the extent to which a behavior was perceived as a lie. Stories depicting egoistic lies only had the sender and receiver of a lie, while other-oriented lies could also have a third person. Other-oriented lies were thus designed to be aimed at depicting the benefits of either the receiver of the communication or a third person (e.g., in the story: "Person A planned a romantic date for the evening with person $B$, with whom he/she is in a relationship. Person $B$, not aware of any plans of person A, informs him/her that he/she already made an appointment for that night with friends, which he/she really feels like sticking to. Person A tells person $B$ to go out with friends and enjoy himself/herself, and that he/she did not have any plans for the evening," person B benefited and in the story "Person A tells person $B$ (his/her supervisor) that person $C$ is a co-author of a project, in which person $C$ was supposed to take part, although in reality person $C$ did not take part in it," the benefits of person $\mathrm{C}$ were taken into consideration). Overall descriptive statistics are presented in Table 1.

Evaluations of mean deceitfulness of the stories in the overall sample ranged from 57.67 to $91.37(M=77.48$, $S D=17.83)$. Six stories that were perceived as lies to the lowest extent (up until 71.62\%) were all other-oriented lies and seven stories that were perceived as the most deceptive were all egoistic (from $84.54 \%$ up). Interestingly, three of the other-oriented stories did not even reach $50 \%$ of deceitfulness in the evaluations of participants from at least two countries.

We then conducted mediation analysis with the benefits of others as a predictor of perceived deceitfulness of the behavior and the extent to which a behavior was evaluated as good as a mediator. We used standardized variables in the analysis. We conducted this analysis on the joined sample and in each of the samples from the seven countries separately as well.

The results of the mediation analysis on the joined sample showed that perceived benefits of another person were negatively related to the perceived deceitfulness of a behavior $b^{*}=-.17, p<.001,95 \%$ CI $[-0.22,-0.11]$, but when the moral judgment of such behavior was controlled for, perceived benefits of others were no longer significantly related to the perception of deceitfulness of such a behavior $b^{*}=-.03, p=.246,95 \%$ CI $[-0.08,0.02]$. The extent to which a behaviour was assessed as good was negatively related to its perceived deceitfulness $b^{*}=-.37, p<.001,95 \%$ CI [-0.43, -0.32]. Perceived benefits of another person were positively related to the degree to which the behavior was evaluated as good $b^{*}=.37, p<.001,95 \%$ CI [0.32, 0.42]. This mediation effect was additionally confirmed with the results of the Sobel test, $Z=-9.93, p<.001$. These results are graphically displayed in Figure 1.

We then conducted the same analysis on each of the samples separately. Though the total effects of benefits of another on perceived deceitfulness did not reach the conventional $\mathrm{p}<.05$ in the case of two countries, the Sobel test indicated a significant mediation effect in each of the samples (Table 2).

A similar analysis with benefits of the liar as a predictor showed no significant relationship between this variable and the extent to which a behavior was perceived as good, or perceived deceitfulness of a behavior in five out of seven countries, indicating no grounds for conducting a mediation analysis.

Importantly, we tested mediation analysis with the benefits of another as predictor and moral judgment as an outcome variable mediated with perceived deceitfulness in the seven samples. In all the seven countries there was no full mediation. Namely, the direct effect of benefits of another was still significant when controlled for perceived

Table 1. Means and standard deviations of the variables analyzed in Study 1 and Study 2

\begin{tabular}{ccccccccc} 
& Benefits of the liar & \multicolumn{2}{c}{$\begin{array}{c}\text { Benefits of another } \\
\text { person }\end{array}$} & \multicolumn{2}{c}{ Moral judgment } & \multicolumn{2}{c}{ Lie labelling } \\
\hline & $\boldsymbol{M}$ & $\boldsymbol{S D}$ & $\boldsymbol{M}$ & $\boldsymbol{S D}$ & $\boldsymbol{M}$ & $\boldsymbol{S D}$ & $\boldsymbol{M}$ & $\boldsymbol{S D}$ \\
\hline Study 1 & 4.62 & 0.89 & 3.59 & 0.63 & 2.95 & 0.72 & 77.48 & 17.83 \\
\hline Study 2 & 4.21 & 1.17 & 3.91 & 1.27 & 3.38 & 1.13 & 5.66 & 1.02 \\
\hline
\end{tabular}

Note. In Study 1 lie labeling was measured on a $0=$ definitely not a lie, to $100 \%=$ definitely a lie scale. The rest of the variables were measured on a 1-7 scale with higher numbers indicating greater intensity of a characteristic. 


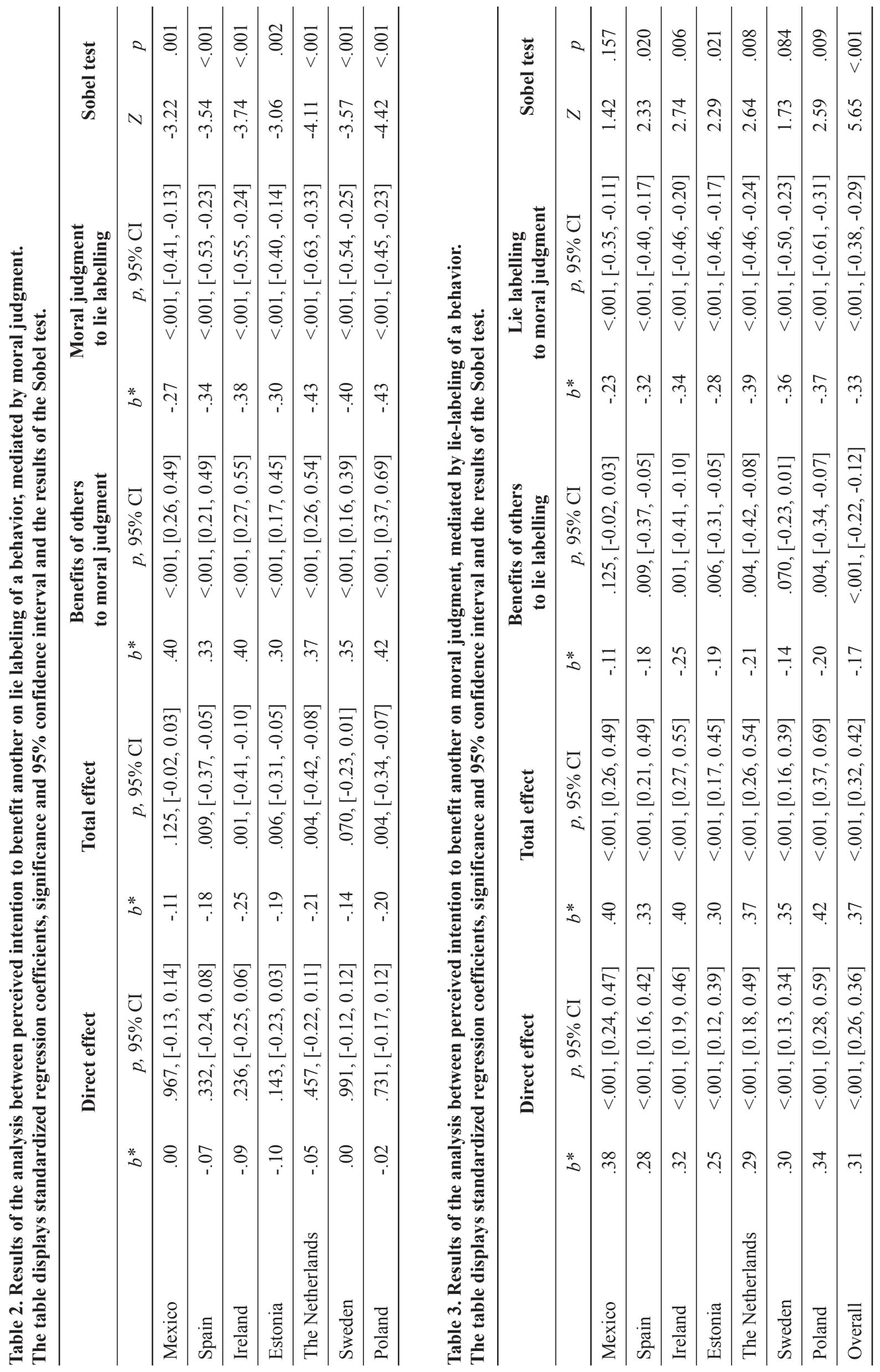


Figure 1. Results of Study 1 presenting the standardized estimates of the relationship between perception of the intention to benefit another to perceived deceitfulness of an act mediated by the moral judgment. The standardized regression coefficient of the benefits of others to perceived deceitfulness when controlling for the moral judgment is presented in parenthesis

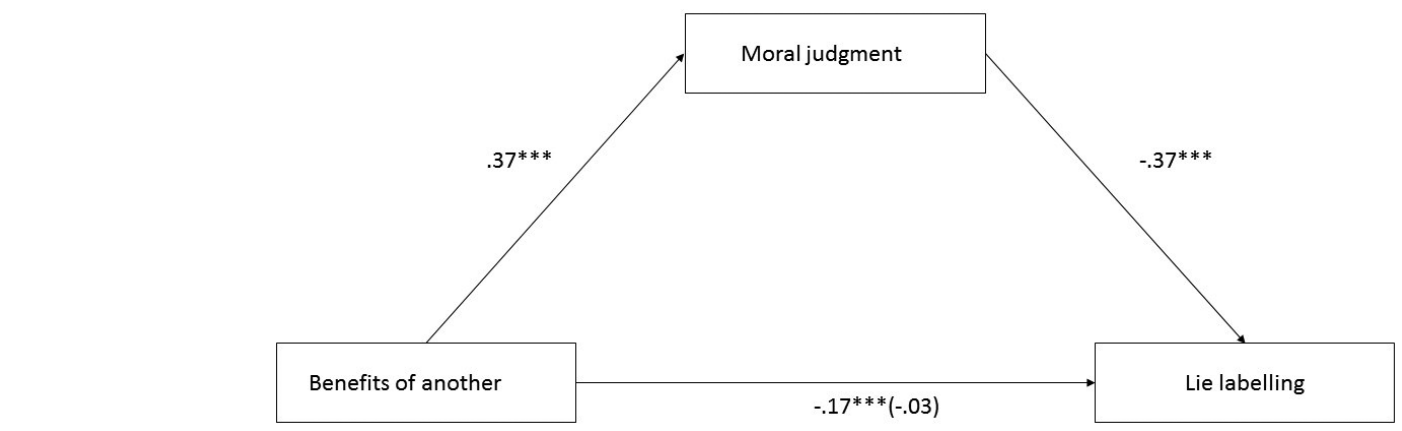

$* * * \mathrm{p}<.001$

deceitfulness in every case. An additional analysis with the Sobel test indicated no significant indirect effect in two out of seven countries. These results are presented in Table 3.

\section{Study 2}

Study 1 was of a correlational design and we did not measure perceived consequences for another, but the perception of the intentions of the liar to benefit another We designed Study 2 to show that manipulations of perceived benefits of others influence the extent to which intentionally misleading someone in order to foster a false belief is perceived as a lie. Again, we also wanted to test a mediation analysis with moral judgment of the act as a mediator.

\section{Participants and Procedure}

One hundred and seventeen Polish students (96 women, $M_{a g e}=26.71, S D_{a g e}=7.28$ ) took part in an online experiment. Participants were asked to read descriptions of four situations and then evaluate them.

\section{Materials}

We prepared four stories that were designed to show intentional acts of misleading someone in order to foster a false belief. Two stories depicted work related matters and two other stories were set in a private life context. The stories were then manipulated, so that they indicated that the act of intentionally misleading someone in order to foster a false belief was either self-centered or otheroriented (see Appendix 1). We did not use the word 'lie' when depicting the stories. In the stories, the protagonist, person $\mathrm{A}$, intentionally misled person $\mathrm{B}$ in order to foster a false belief. Half of participants were presented with the self-centered stories and half were shown the otheroriented stories. Each participant viewed the four stories in random order. Under each story, participants were asked to state the extent to which the behavior of the protagonist (person A) was good, was a lie, brought benefits to person $\mathrm{B}$, and brought benefits to person $\mathrm{A}$ on a $1=$ definitely not, to $7=$ definitely yes scale.

\section{Results}

We first calculated mean replies of the extent to which the four stories were evaluated as good $(\alpha=.65)$, as a lie $(\alpha=.77)$, benefitting the lied to $(\alpha=.65)$ and benefitting the $\operatorname{liar}(\alpha=.63)$. The overall descriptive statistics are presented in Table 3

We then conducted a MANOVA analysis with the type of lie (self-centered vs. other-oriented) as an independent variable and the four variables (moral judgment, evaluation as a lie, benefits of the lied to, benefits of the liar) as dependent variables. The results showed that the differences between the means were statistically significant, Pillai's trace $V=.63, F(4,112)=48.42, p<.001$. A separate ANOVA revealed that the behavior of the protagonist was perceived as good to a higher extent when the stories were designed as other-oriented $(M=4.12, S D=.92)$ than when they were self-centred $(M=2.55, S D=.67)$, $F(1,115)=108.77, p<.001, \eta^{2}=.49$. Other-oriented intentional misleading in order to foster a false belief was also perceived as lying to a lower degree $(M=5.35$, $S D=1.14)$ than when the behavior was self-centered $(M=6.00, S D=.73), F(1,115)=12.74, p=.001, \eta^{2}=.10$. We also found that our manipulation was successful in that participants perceived the other-oriented intentional misleading in order to foster a false belief as benefiting person B to a higher extent $(M=4.74, S D=1.00)$, than the self-centered one $(M=2.99, S D=.81), F(1,115)=106.17$, $p<.001, \eta^{2}=.48$. Similarly, stories presenting self-centered deviations from truth were perceived as bringing benefits to the protagonist to a higher extent $(M=4.61, S D=1.27)$, than the stories depicting other-oriented intentional misleading in order to foster a false belief $(M=3.85$, $S D=.95), F(1,115)=13.52, p<.001, \eta^{2}=.11$.

We then conducted a mediation analysis with the experimental condition as an independent variable (dummy coded, where 1 stood for other-oriented), moral judgment as a mediator and perceived deceitfulness as an outcome variable following recommended practices in conducting mediation analyses (Hayes, 2013).

The results of the mediation analysis showed that manipulating the benefits of the lied to was negatively 
Figure 2. Results of Study 2 presenting the standardized estimates of the relationship between perception of the benefits others to perceived deceitfulness of an act mediated by the moral judgment. The standardized regression coefficient of the benefits of others to perceived deceitfulness when controlling for the moral judgment is presented in parenthesis

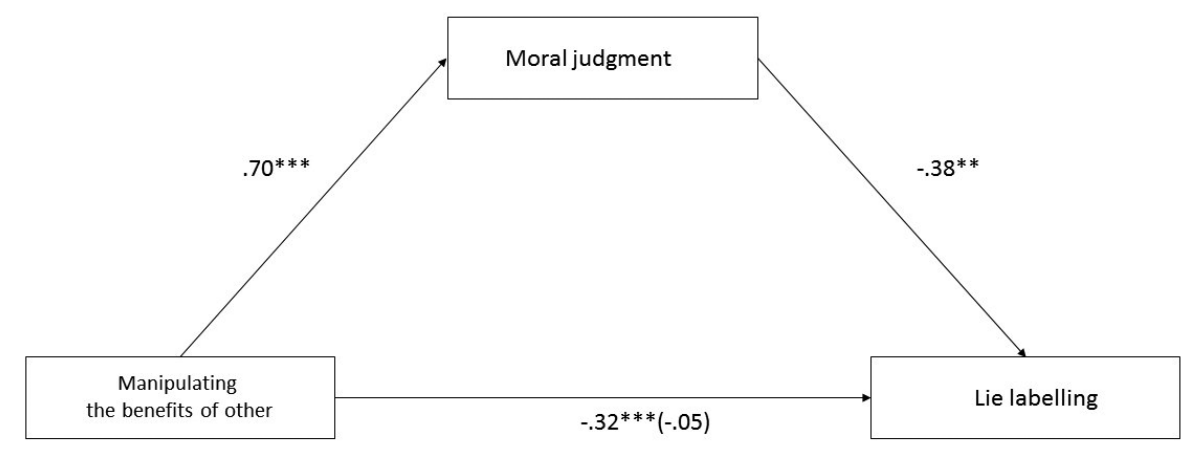

$* * \mathrm{p}<.01, * * * \mathrm{p}<.001$

related to the perceived deceitfulness of a behavior $b^{*}=-.32, p<.001,95 \%$ CI $[-1.00,-0.29]$, but when the moral judgment of such behaviour was controlled for, the benefits of others were no longer significantly related to the perception of deceitfulness of such a behavior $b^{*}=-.05$, $p=.664,95 \%$ CI $[-0.58,0.37]$. The moral judgment was negatively related to the perceived deceitfulness $b^{*}=-.38$, $p=.002,95 \%$ CI $[-0.55,-0.13]$. The benefits of another person were positively related to the moral judgment of the behavior $b^{*}=.70, p<.001,95 \%$ CI $[1.27,1.87]$. This mediation effect was additionally confirmed with the results of the Sobel test, $Z=-2.96, p=.002$. These results are presented in Figure 2.

We then conducted the analysis with the benefits of the liar as a predictor. The results were similar to those in Study 1, that is, there was no significant relationship between this variable and the extent to which a behavior was perceived as good, or perceived deceitfulness of a behavior, indicating no grounds for conducting a mediation analysis.

We also tested mediation analysis with the benefits of another as predictor and moral judgment as an outcome variable mediated with perceived deceitfulness. The results of such an analysis indicated that when we control for the perceived deceitfulness of a behavior $b^{*}=-.22, p=.001$, $95 \%$ CI $[-1.00,-0.29]$, the manipulated benefits of the other person are still a significant predictor of the moral judgment $b^{*}=.63, p<.001,95 \%$ CI $[1.12,1.72]$. The Sobel test, however, indicated a significant indirect effect $Z=-2.88$, $p=.003$.

\section{Discussion}

The results of Study 1 showed that the more an act of intentional misleading in order to foster a false belief is perceived as intended to benefit others, the less it is perceived as a lie and that this relationship is mediated by the moral judgment of that act. Importantly, this relationship held true not only in the joint sample of the data of participants from seven countries, but also in each of the countries separately. We also showed that when the moral judgment of that behavior is analyzed as an outcome variable, such a mediation model is not as well suited to the data. Neither full nor partial mediation was present in each of the countries. Study 2 complemented these findings by showing that manipulations of the benefits of others influence both the moral judgment and labeling an act of intentional misleading in order to foster a false belief as a lie. A similar mediation analysis showed that perceived benefits of others influence identification of a lie and that this relationship is mediated by the moral judgment. Similar to Study 1, we conducted the mediation analysis to see whether the lie-labeling can serve as a mediator. We did find significant partial mediation that cannot disclaim such a possibility. Importantly, in accordance with the dyadic morality stance, we found that it is the benefits of others (or lack of thereof) and not the benefits of the liar that are crucial for the moral judgment.

It seems important to investigate lay definitions of lying for both theoretical and applicable reasons. First of all, it is important to know whether research on intentional acts of misleading in order to foster a false belief is indeed research on lying as defined by scientists and/or as defined by participants. Should a researcher choose to focus on the scientific definition only, they have to be aware that, at times, they may instead be investigating a socially accepted norm of deviating from truth. Lying, and above all self-centered lying, is in general negatively perceived (e.g., Inglehart, Basanez, \& Moreno, 1998), though there are significant cross-cultural differences in this regard (e.g., Aune \& Waters, 1994; Mealy, Stephan, \& Urrutia, 2007; Fu, Xu, Cameron, Heyman, \& Lee, 2007). It seems of vital importance to know whether cultural differences regarding attitudes towards lying indeed measures attitudes towards lying, as results of such studies may bring consequences to social perceptions of cultures. Second of all, there are countless studies on lying detection (e.g., Ekman, \& Friesen, 1969; DePaulo et al., 2003; Strömwall, \& Granhag, 2003; ten Brinke, Vohs, \& Carney, 2016; Granhag, 2006; Granhag, Vrij, \& Verschuere, 2015). Lay 
definitions of lying can be a significant factor related to the extent to which one finds it aversive to intentionally mislead someone in order to foster a false belief depending on whether s/he perceives that act as a lie, or not. Finally, there are important legal consequences of the way people define lying. Laws are often passed independent of scientific knowledge regarding an issue. For example, in the United States, judges forbid the witnesses in a trial to wear the niqab (a type of face veil), supposedly because it could difficult lying detection. This notion is in line with lay perceptions of when people lie and what the perceived cues to detection are (e.g., Lakhani, \& Taylor, 2003; Global Deception Research Team, 2006). Research shows, however, that lying detection based on communications sent by a person with their face hidden are even more accurate compared to when there is no face veil (Leach et al., 2016). Lay definitions and perceptions of psychological phenomena may even have a larger impact on legal matters than scientific findings. There are thus various reasons why it is important to investigate lay definitions of lying and control for this factor when conducting scientific research on this matter.

There are some limitations to the findings presented here. The design of the studies does not allow conclusions to be drawn on causality regarding whether the moral judgment comes before or after lie labeling. Though the mediation analysis had the best fit when we used benefits of others as a predictor, moral judgment as a mediator and perceived deceitfulness as an outcome variable, only future experimental studies can show that this pattern of results indicates causality. We repeatedly used one-item measures of moral judgment. We considered it appropriate for use in our studies and thought that such a straightforward measure would be valid to assess the moral judgment understood as evaluating the extent to which something is good or bad (e.g., Haidt, 2001). However, we do acknowledge the limitations of the use of a one-item measure. Additionally, not all of the measures used in Study 2 reached good reliabilities. It is possible that is was due to the fact that the measures were based on few items and the number of items influences Cronbach's alpha (see, e.g., Cortina, 1993). Future studies can benefit from the use of multi-item scales to measure lie labeling or moral judgments. We also acknowledge the limitations of conducting research using vignettes. We know that real-life situations and reactions to such situations may differ from reading a story about a "Person A". We do feel, however, that the benefits of being able to highly control the conditions of the study are important. What is more, given that the research question was focused on lie-labeling and moral judgment and not on behavior (e.g., when do people lie), we consider the vignettes a not perfect, but still a proper research material.

Future studies can focus on the cultural aspect of defining lying. Some researchers suggest that the definition of lying is rather universal and that culture, above all, influences the variability in the goals that lying is aimed to achieve (Sweetser, 1987). It is possible, however, that lay definitions of lying may in fact be different depending on the culture of the individual. The results of Study 1 suggest that the benefits of others might be related to cross-cultural differences in defining lying. Another interesting avenue of research may be to focus on the stake of a lie with reference to lie-labeling. All things being equal, acts of intentionally misleading someone in order to foster a false belief that are of a high stake will probably be perceived as lies to a higher extent than when the stakes are low.

In Study 1 we asked whether a behavior was motivated to bring benefits to the liar and to another person. Study 2 was focused on the perceptions of the consequences of the behavior for the liar and for another person. Both proved to be important factors regarding labeling an act as a lie. It would be interesting to manipulate and separate intentions to benefit/harm another from the positive/ negative consequences of lying. The traditional view on moral development suggests that at higher stages of moral development, children pay more attention to the intentions and not consequences in their evaluations and definitions of lying (e.g., Piaget, 1967; Bulla, 2006). Recent findings regarding the importance of harm, or lack of thereof, in moral judgments (e.g., Gray, Schein, \& Ward, 2014) suggest that the consequences of a lie may still be a strong(er) predictor of both accepting and defining lying.

There are some factors that seem to be crucial for lay definitions of lying. Belief in the falsity of the information is thought to be the most important one (Coleman \& Kay, 1981). Perceptions of benefits of others come as an unobvious waiver that makes that intentional act of misleading someone in order to foster a false belief less of a lie. Is an intentional act of misleading someone to foster a false belief bad because it is a lie, or is it a lie because it is bad? The results presented in this paper cannot answer this question. It seems likely though that this relationship may go both ways. The aim of this article was to show that labeling an act of intentional misleading in order to foster a false belief as a lie depends on the perception of benefits of another person. Drawing from theoretical works regarding the formulation of moral judgments, it seemed most proper to assume that this relationship is mediated by the moral judgment of that behavior. We think that these results make a valuable contribution to understating the formation of lay definitions of lying nd offer new avenues for research on this subject.

\section{References}

Antas, J. (2008). O kłamstwie i kłamaniu. Kraków: UNIVERSITAS

Aune, R.K., \& Waters, L.L. (1994). Cultural differences in deception: motivations to deceit in Samoans and North Americans. International Journal of Intercultural Relations, 18, 2, 159-172.

Bok, S. (1982). Secrets: On the ethics of concealment and revelation. Michigan: Pantheon Books.

Bugnyarf1, T., \& Kotrschal, K. (2002). Observational learning and the raiding of food caches in ravens, Corvus corax: is it 'tactical' deception? Animal Behaviour, 64, 2, 185-195.

Bulla, B. (2006). Ocena poziomu rozwoju moralnego dziecka w wieku przedszkolnym. In Z. Dołęga (Ed.), Diagnoza psychologiczna dzieci w wieku przedszkolnym (pp. 154-185). Katowice: Wydawnictwo Uniwersytetu Śląskiego.

Buller, D.B., \& Burgoon, J.K. (1996). Interpersonal Deception Theory. Communication Theory, 6, 3, 203-242. 
Cantarero, K. (2014). Kłamstwo a manipulacja. In D. Doliński, M. Gamian-Wilk (Eds.) Przestrzenie manipulacji spolecznej, pp. 60-82. Warszawa: PWN

Cantarero, K., Szarota, P., Stamkou, E., Navas, M., \& Dominguez Espinosa, A. (in press). When is a lie acceptable? Work and private life lying acceptance depends on its beneficiary. The Journal of Social Psychology, doi:10.1080/00224545.2017.1327404.

Cheung, H., Chan, Y., \& Tsui, W.C.G. (2016). Effects of lie labelling on children's evaluations of selfish, polite, and altruistic lies. British Journal of Developmental Psychology, 34, 325-339.

Cheung, H., Siu, T.C., \& Chen, L. (2015). The roles of liar intention, lie content, and theory of mind in children's evaluation of lies. Journal of Experimental Child Psychology, 132, 1-13.

Coleman, L., \& Kay, P. (1981). Prototype semantics: The English word lie. Language, 57, 26-44.

Cortina, J.M. (1993). What is coefficient alpha? An examination of theory and applications. Journal of Applied Psychology, 78, 98-104.

DePaulo, B.M., Kirkendol, S.E., Kashy, D.A., Wyer, M.M., \& Epstein, J.A. (1996). Lying in everyday life. Journal of Personality and Social Psychology, 70, 5, 979-995.

DePaulo, B., Lindsay, J.J., Malone, B.E., Muhlenbruck, L., Charlton, K, \& Cooper, H. (2003). Cues to deception. Psychological Bulletin, $129,1,74-118$

Doliński, D. (1996). The mystery of Polish soul. B.W. Johnson's effect à rebours. European Journal of Social Psychology, 26, 6, 1001-1005.

Eichelberger, J. (2013). A semantic and pragmatic analysis of the Spanish word lie: Implications and applications for the second language learner. South Central Modern Language Association, October 2013, New Orleans.

Ekman, P. (1985). Telling lies. Clues to deceit in the marketplace, politics and marriage. New York: Norton.

Ekman, P., \& Friesen, W. (1969). Nonverbal leakage and clues to deception. Psychiatry, 32, 1, 88-106.

Fu, G., Xu, F., Cameron, C.A., Heyman, G., \& Lee, K. (2007). Cross-cultural differences in children's choices, categorizations, and evaluations of truths and lies. Development Psychology, 43, 2, 278-293.

Global Deception Research Team. (2006). A world of lies. Journal of Cross Cultural Psychology, 37, 60-74.

Granhag, P.A. (2006). Rethinking implicit lie detection. The Journal of Credibility Assessment and Witness Psychology, 7, 3, 180-190

Granhag, P.A., Vrij, A., \& Verschuere, B. (2015). Detecting deception: Current challenges and cognitive approaches. Chichester: WileyBlackwell.

Gray, K., \& Keeney, J. (2015). Disconfirming Moral Foundations Theory on its own terms: Reply to Graham (2015). Social Psychological and Personality Science, 1-4.

Gray, K., \& Schein, C. (in press). No absolutism here: Harm predicts moral judgment 30x better than disgust-Commentary on Scott, Inbar \& Rozin (2015). Perspectives on Psychological Science.

Gray, K., \& Schein, C. (2012). Two minds vs. two philosophies: Mind perception defines morality and dissolves the debate between deontology and utilitarianism. Review of Philosophy and Psychology, 3, $1-19$.

Gray, K., Schein, C., \& Ward, A.F. (2014). The myth of harmless wrongs in moral cognition: Automatic dyadic completion from sin to suffering. Journal of Experimental Psychology: General, 143, 1600-1615

Gray, K., Young, L., \& Waytz, A. (2012). Mind perception is the essence of morality. Psychological Inquiry, 23, 101-124.

Haidt, J. (2012). The righteous mind: Why good people are divided by politics and religion. New York: Pantheon Books.

Haidt, J. (2001). The emotional dog and its rational tail: A social intuitionist approach to moral judgement, Psychological Review, 108, 4, 814-834.

Haidt, J., \& Joseph, C. (2004). Intuitive ethics: How innately prepared intuitions generate culturally variable virtues, Daedalus, 133, 4, 55-66.

Haidt, J., Koller, S.H., \& Dias, M.G. (1993). Affect, culture and morality, or is it wrong to eat your dog? Journal of Personality and Social Psychology, 65, 4, 613-628.
Hayes, A.F. (2013). Introduction to Mediation, Moderation, and Conditional Process Analysis. A Regression-Based Approach. New York: Guilford Publications.

Hardin, K.J. (2010). The Spanish notion of lie: Revisiting Coleman and Kay. Journal of Pragmatics, 42, 12, 3199-3213.

Holling, C.S. (1965). The functional response of predators to prey density and its role in mimicry and population regulation. The Memoirs of the Entomological Society of Canada, 97, 5-60.

Inglehart, R., Basañez, M., \& Moreno, A. (1998) Human values and beliefs. A cross-cultural sourcebook: political, religious, sexual and economic norms in 43 societies. Michigan: The University of Michigan Press.

Kim, M.S., Kam, K.Y., Sharkey, W.F., \& Singelis, T.M. (2008). Deception: Moral transgression or social necessity? Cultural-relativity of deception motivations and perceptions of perceptive communication. Journal of International and Intercultural Communication, 1, 23-50.

Kohlberg, L. (1976). Moral stages and moralization: The cognitive-developmental approach. In T. Lickona (Ed.). Moral development and behavior: Theory, research, and social issues (pp. 31-55). Nowy Jork: Holt, Rinehart, and Wisconsin.

Kohlberg, L., \& Hersh, R.H. (1977). Moral Development: A Review of The Theory. Theory into Practice, 16, 2, 53-59.

Kuczaj, S., Tranel, K., Trone, M., \& Hill, H. (2001). Are animals capable of deception or empathy? Implications for animal consciousness and animal welfare. Animal Welfare, 10, 161-173.

Leach, A.-M., Ammar, N., England, N.D., Remigio, L.M., Kleinberg, B., $\&$ Verschuere, B. (2016). Less is more? Detecting lies in veiled witnesses. Law and Human Behavior, 40, 4, 401-410.

Lee, K., Cameron, C.A., Xu, F., Fu, G., \& Board, J. (1997). Chinese and Canadian children's evaluations of lying and truth telling: Similiarities and differences in the context of pro- and antisocial behaviors. Child Development, 68, 5, 924-934.

Levine, E.F., \& Schweitzer, M. (2014), Are liars ethical? On the tension between benevolence and honesty. Journal of Experimental Social Psychology, 53, 107-117.

Levine, T.R., Ali, M.V., Dean, M., Abdulla, R.A., \& Garcia-Ruano, K (2016). Toward a Pan-cultural Typology of Deception Motives, Journal of Intercultural Communication Research, 45, 1, 1-12.

Lakhani, M., \& Taylor, R. (2003). Beliefs about cues to deception in highand low-stake situations. Psychology, Crime \& Law, 9, 4, 357-368.

Lindskold, S., \& Walters, P.S. (1983). Categories for acceptability of lies The Journal of Social Psychology, 120, 129-136.

Masip, J., Garrido, E., \& Herrero, C. (2004). Defining deception. Anales de psicologia, 20, 1, 147-171.

McCloskey, M. (1983). Intuitive physics. Scientific American, 284, 4 $122-130$.

Mealy, M., Stephan, W., \& Urrutia, C.I. (2007). The acceptability of lies: a comparison of Ecuadorians and Euro-Americans. International Journal of Intercultural Relations, 31, 689-702.

Ning, S.R., \& Crossman, A.M. (2007). We believe in being honest: Examining subcultural differences in the acceptability of deception. Journal of Applied Social Psychology, 37, 2130-2155.

Parzuchowski, M., Bocian, K., \& Wojciszke, B. (2016). Od skrajności do codzienności: współczesna psychologia ocen moralnych. Psychologia społeczna, 39, 4, 388-398.

Piaget, J. (1967). Rozwój ocen moralnych dziecka. Warszawa: PWN.

Schein, C., Goranson, A., \& Gray, K. (2015). The uncensored truth about morality. The Psychologist, 28(12), 982-985.

Schwab, A. (2013). Deception by omission. The American Journal of Bioethics, 13, 11, 52-53.

Shweder, R.A., Mahapatra, M., \& Miller, J.G. (1987). Culture and moral development. In J. Kagan, \& S. Lamb (Eds), The emergence of morality in young children (pp. 1-83). Chicago: University of Chicago Press.

Shweder, R.A., Much, N.C., Mahapatra, M., \& Park, L. (1997). The "big three" of morality (autonomy, community, and divinity), and the "big three" explanations of suffering. In A. Brandt \& P. Rozin (Eds.), Morality and health (pp. 119-169). New York: Routledge.

Strömwall, L.A., \& Granhag, P.A. (2003). How to detect deception? Arresting the beliefs of police officers, prosecutors and judges. Psychology, Crime \& Law, 9, 19-36. 
Sweetser, E. (1987). The definition of lie. In N. Quinn, D. Holland (Eds.), Cultural Models in Language and Thought (pp. 43-66). Cambridge University Press.

ten Brinke, L., Vohs, K.D., \& Carney, D.R. (2016). Can ordinary people detect deception after all? Trends in Cognitive Sciences, 20, 8 , 579-588.

Turri, A., \& Turri, J. (2015). The truth about lying. Cognition, 138, $161-168$
Wimmer, H., Gruber, S., \& Perner, J. (1985). Young children's conception of lying: Moral intuition and the denotation and connotation of 'to lie'. Developmental Psychology, 21, 993-995.

Wojciszke, B., \& Baryła, W. (2002). Jak odstrzelić sobie nogę: psychologiczne konsekwencje narzekania. Kolokwia Psychologiczne, 10, 213-235.

Wojciszke, B., Parzuchowski, M., \& Bocian, K. (2015). Moral judgments and impressions. Current Opinion in Psychology, 6, 50-54.

\section{APPENDIX 1}

Stories presented in Study 2. The stories were originally presented in Polish. The Polish version of the stories is available upon request from the corresponding author of the article.

A) Self-centred stories

1. Person A and person B work together in the same company. Person B says that the supervisor wants one of them to stay overtime and perform additional paid work. Person A says that she can't because she's busy, but in fact she doesn't have anything to do after work. However, she doesn't want to stay at work any longer, and hopes that person B will take the overtime hours.

2. Person A and person B work together in the same company. One of their tasks was to prepare an application for a particular project. As a result of the division of work, person A was supposed to finish the task. When asked by person B if the application for the project had been submitted, person A said it was already done, while in fact it had not yet been closed. Person A knows that he will soon be done with it and does not want to hear any stinging remarks from person B.

3. Person A and person B have known each other for a long time. Person B asks person A if she likes a certain dress, and if she should buy it for herself. Although person A likes the dress, she tells person B that it's ugly and she shouldn't buy it. In fact, person A would like to buy the dress herself and wants to discourage person B from buying it.

4. Person A and person B have known each other for a long time. During a hiking trip, person B asks person A if he's feeling tired. Person A responds that he's not tired, but in fact he is already very tired, running out of energy, and does not want to continue walking. However, person A does not want person B to think that he is worse and in weaker physical condition.

B) Other-oriented stories

1. Person A and person B work together in the same company. Person B says that the supervisor wants one of them to stay overtime and perform additional paid work. Person A says that she can't because she's busy, but in fact she doesn't have anything to do after work. Person A wants person B to take the hours, because she knows that person B really needs the money and would like to work overtime.

2. Person A and person B work together in the same company. One of their tasks was to prepare an application for a particular project. As a result of the division of work, person A was supposed to finish the task. When asked by person B if the application for the project had been submitted, person A said it was already done, while in fact it had not yet been closed. Person A knows that he will soon be done with it, and if he tells person B that it's not yet finished, he knows that person B will want to help. Person A is aware that this means person B might not manage to finish the new tasks his superior has given to him.

3. Person A and person B have known each other for a long time. Person B asks person A if she likes a certain dress, and if she should buy it for herself. Although person A likes the dress, she tells person B that it's ugly and she shouldn't buy it. In fact, person $\mathrm{A}$ has just bought that dress as a present for person $\mathrm{B}$, and wants to discourage her from buying it.

4. Person A and person B have known each other for a long time. During a hiking trip, person B asks person A if he's feeling tired. Person A responds that he's not tired, but in fact he is already very tired, running out of energy, and does not want to continue walking. Person A knows that person B loves hiking trips. He also knows that if he admits to being tired, person B will not want person A to suffer, and will finish the trip. 